\title{
VALIDATION OF A SYNDROMIC SURVEILLANCE SYSTEM USING A GENERAL PRACTITIONER HOUSE CALLS NETWORK, BORDEAUX, FRANCE
}

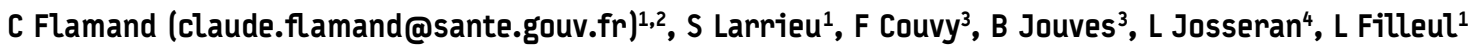 \\ 1. Institut de Veille Sanitaire (InVS), Cellule Interrégionale d’épidémiologie (Cire) Aquitaine, Bordeaux, France \\ 2. Programme de Formation à l’Epidémiologie de Terrain (PROFET), InVS, Saint-Maurice, ENSP, Rennes, France \\ 3. SOS Médecins Bordeaux, Bordeaux, France \\ 4. Institut de Veille Sanitaire (InVS), Direction Générale, Saint-Maurice, France
}

\begin{abstract}
A new syndromic surveillance system has been developed in Bordeaux City, South West France, using a general practitioners' house calls network. Routinely collected, sociodemographic data, patients' complaints and medical diagnoses made at the end of the visit were monitored using syndrome groups such as influenza syndromes, bronchiolitis, gastrointestinal, respiratory syndromes and others, based on International Classification of Primary Care (ICPC)-2 codes. A process control chart was implemented in order to distinguish signals of interest from "background noise". In 2005 and 2006, a total of 303,936 visits were recorded. Seasonal epidemics of influenza-like illness, bronchiolitis or gastrointestinal were identified. The automated and real time nature of the system also allowed the early detection of unusual events such as an acute increase in the number of heat syndromes during the heat-wave that occurred in France in July 2006. This new system complements existing surveillance programs by assessing a large part of episodes of illness that do not require hospital admissions or the identification of an etiologic agent. Attributes and advantages of the system, such as timeliness and diagnostic specificity, demonstrated its utility and validity in term of syndromic surveillance purposes, and its extension at the national level is in process.
\end{abstract}

\section{Introduction}

Recent health events in France, such as the dramatic excess of mortality occurred during the heat-wave in 2003 [1] showed the need for a better provision of information to health authorities to help them with the decision-making process [2]. Enhancing public health surveillance to include electronic syndromic surveillance [3] has received increased attention in recent years [4-9]. In July 2004, the French institute for public health surveillance (Institut de Veille Sanitaire, InVS) initiated a pilot network, based on different sources of data available in real time from hospital emergency departments and mortality registry offices [9]. These daily collected data can be used for early detection of abnormal health-related events or to quantify the health impact of major events. However, hospital emergency and mortality data reflect the most severe forms of the diseases and some disease outbreaks could escape detection, if not associated with significant hospital admissions or excess mortality. It seems therefore necessary to gather multiple sources of data on various health problems to improve the monitoring of population health, notably through general practitioners (GPs) who might be particularly useful information providers. In this context, an information system based on a computer network of physicians (the Sentinel network) has been developed in France since 1984 [10]. This continuous and ongoing national surveillance network is constituted of voluntary sentinel practitioners all over the country and allows the monitoring of 14 communicable diseases or health events (acute diarrhea, asthma attack, chickenpox, hepatitis A, $B$ and $C$, herpes zoster, hospitalization, influenza-like illness, male urethritis, measles, mumps, hepatitis $C$ serologies, suicidal attempts), with weekly data analysis [10, 11]. However, in order to detect various outbreaks and to identify sanitary alert, surveillance systems must be conduced both nationally and locally and a wide range of specific health outcomes must be monitored. In particular, the emergence of new infectious hazards [12] such as Severe acute respiratory syndrome (SARS), potential bioterrorist-initiated [13] outbreaks or avian influenza, makes it necessary to increase public health surveillance systems which can identify these types of risks on an urban area scale.

The Aquitaine regional epidemiology unit (Cellule Interrégionale d'Epidémiologie, Cire), located in Bordeaux, which is the regional office of the InVS is in charge of coordinating public health surveillance in the Aquitaine area, the south-western region of France. In collaboration with SOS Médecins Bordeaux, an organization of general practitioners, the Cire developed a new syndromic surveillance system based on GP's house visits in the Bordeaux area.

The aim of this paper is to describe the functioning of such a surveillance system and to give some examples of application.

\section{Methods}

\section{General description of the network}

Founded in 1966, SOS Médecins is the most important GP emergency and healthcare network in France. It consists of 60 local organisations spread across the country, responding to private houses calls 24 hours a day, seven days a week. Patients in need of a home medical visit can request it from the organisation by telephone when their usual general practitioner is not available.

In the urban area of Bordeaux, a city located in southwestern France, SOS Médecins comprises 60 GPs making more than 400 interventions a day. SOS Médecins Bordeaux operates in an area of approximately 800,000 inhabitants. 
Telephone calls are handled by a two-person call centre and logged in a local database. This database is linked via internet to electronic notebooks held by GPs who can update the database with pertinent information following a patient visit. All complaints reported by the patients are coded and recorded according to the International Classification of Primary care (ICPC-2) [14], as well as the final diagnosis.

\section{Data collection and processing}

Daily data are recorded on the secure regional database server. The data collected includes: the date of the visit, postal code, age, sex, the health complaints of the patient and the medical diagnosis. Each morning, the data including all the visits logged during the previous 24-hour period (midnight to midnight) are downloaded from the Cire Aquitaine according to the flow-chart outlined in Figure 1.

\section{Data analysis}

Data have been monitored and analyzed daily everyday from 1 January 2005 to 31 December 2006. The first step is based on the global activity of SOS Médecins Bordeaux with a description of the total number of visits. The second step is a specific analysis based on syndromes groups or particular subgroups of the population (under two years and over 75 years), based on diagnoses made by the doctors. In collaboration with the GPs, ICPC-2 codes were grouped into 16 syndrome groups including influenza, bronchiolitis, gastrointestinal and respiratory syndromes, as well as syndromes linked to high temperature and others (Table 1 ).

F I G U R E 1

SOS Médecins Bordeaux - Cire Aquitaine Syndromic Surveillance flow chart

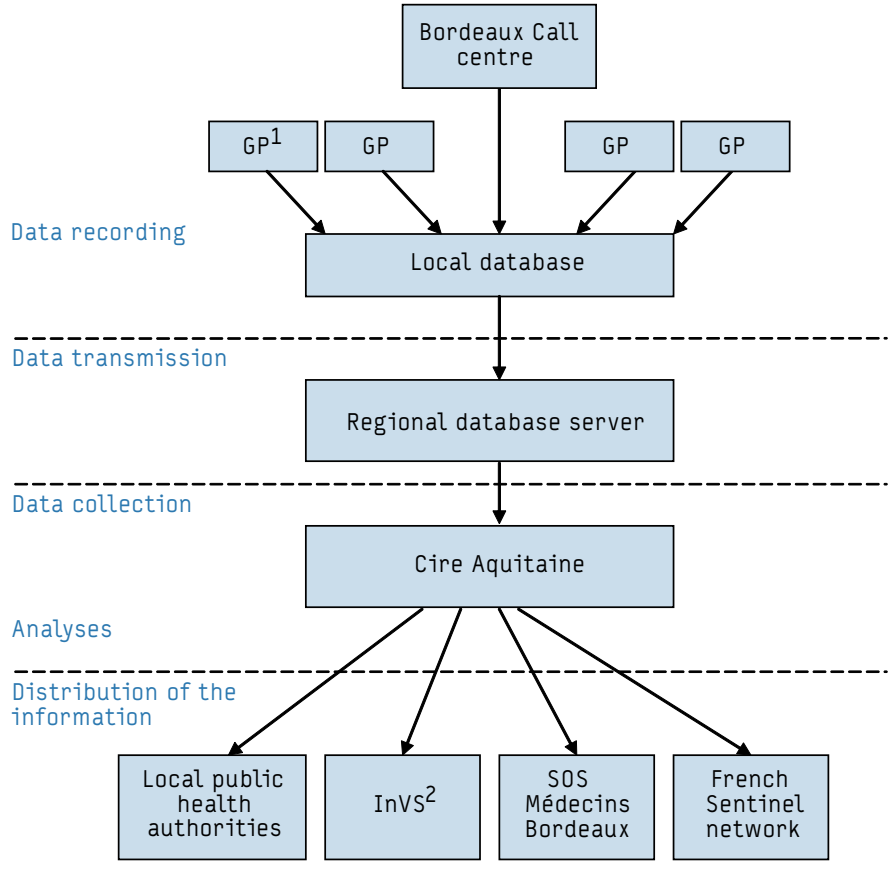

${ }^{1}$ General practitioner

2 Institut de Veille Sanitaire
T A B L E

Syndrome groups under daily surveillance, SOS Médecins Bordeaux - Cire Aquitaine, 1 January 2005 - 31 December 2006

\begin{tabular}{|c|c|c|}
\hline Syndrome groups & $\begin{array}{l}\text { International } \\
\text { Classification } \\
\text { of Primary } \\
\text { Care-2-codes }\end{array}$ & General description \\
\hline \multirow[t]{4}{*}{ Allergy } & S98.01 & Urticaria \\
\hline & R97 & Allergic rhinitis \\
\hline & A92.01 & $\begin{array}{l}\text { Allergy/ allergic reaction not } \\
\text { otherwise specified }\end{array}$ \\
\hline & F71 & Conjunctivitis allergic \\
\hline \multirow[t]{3}{*}{ General imparing } & $\mathrm{A} 04$ & Weakness/tiredness general \\
\hline & A29.02 & General symptom \\
\hline & P29.08 & Psychological symptom \\
\hline \multirow{4}{*}{$\begin{array}{l}\text { Bronchiolitis (in } \\
\text { children under two } \\
\text { years old) }\end{array}$} & R78.01 & Acute lower respiratory infection \\
\hline & R03.02 & Inspiratory wheeze/Asthma \\
\hline & R78.02 & Bronchitis \\
\hline & R02.03 & Dyspnoea \\
\hline \multirow[t]{2}{*}{ Heat syndromes } & A88.01 & Heat burn /Heatstroke \\
\hline & T11 & Dehydratation \\
\hline $\begin{array}{l}\text { Conjunctivitis } \\
\text { infectious }\end{array}$ & F70 & Bacterial/viral conjunctivis \\
\hline \multirow[t]{2}{*}{ Death } & A96 & Death \\
\hline & Z62.02 & Administrative procedure for death \\
\hline \multirow[t]{3}{*}{ Gastrointestinal } & D11 & Diarrhoea \\
\hline & D10 & Vomiting \\
\hline & D73.01 & Gastroenteritis presumed infection \\
\hline \multirow{2}{*}{$\begin{array}{l}\text { Coronary } \\
\text { thrombosis }\end{array}$} & K74.02 & Ischaemic heart disease with angina \\
\hline & K75.02 & Acute myocardial infarction \\
\hline \multirow[t]{3}{*}{ Fainting } & A06 & Fainting / Syncope \\
\hline & K88 & Postural hypotension \\
\hline & N17 & Vertigo/Dizziness \\
\hline \multirow[t]{2}{*}{ Heart failure } & K77 & Heart failure / pulmonary oedema \\
\hline & K29 & $\begin{array}{l}\text { Cardiovascular symptom/Heart } \\
\text { trouble }\end{array}$ \\
\hline $\begin{array}{l}\text { Other respiratory } \\
\text { infection }\end{array}$ & R83 & Rhinitis \\
\hline \multirow[t]{3}{*}{ Influenza } & A77 & Viral disease other \\
\hline & A03.01 & Fever \\
\hline & R80 & Influenza / Influenza-like illness \\
\hline $\begin{array}{l}\text { Viral exanthem } \\
\text { other }\end{array}$ & A76 & Viral exanthem other \\
\hline $\begin{array}{l}\text { Suicide/Suicide } \\
\text { attempt }\end{array}$ & P77 & Suicide/Suicide attempt \\
\hline \multirow[t]{6}{*}{ Urinary infection } & U02 & Urinary frequency/urgency \\
\hline & U71 & Cystitis \\
\hline & U05.01 & Urination problems other \\
\hline & U01 & Dysuria \\
\hline & U95 & Urinary calculus \\
\hline & U70 & Pyelonephritis \\
\hline Chikenpox & A72 & Chikenpox \\
\hline
\end{tabular}


An analysis system using the Shewhart Control Chart for individual measurements based on moving ranges (MR) $[15,16]$ was implemented allowing a continuous real-time assessment in order to immediately detect unusual variations in each of the 16 syndrome groups. This analysis is based on a comparison between the number of reported cases and a control limit calculated on the basis of the average of observations recorded during previous weeks and standard deviation estimated by the moving ranges of size 2 .

\section{F I G U R E 2}

Daily number of visits for seasonal syndromes (influenza, gastrointestinal and bronchiolitis among children under two years old) - SOS Médecins Bordeaux, 1 January 2005 - 31 December 2006 $(n=303,936$ visits $)$
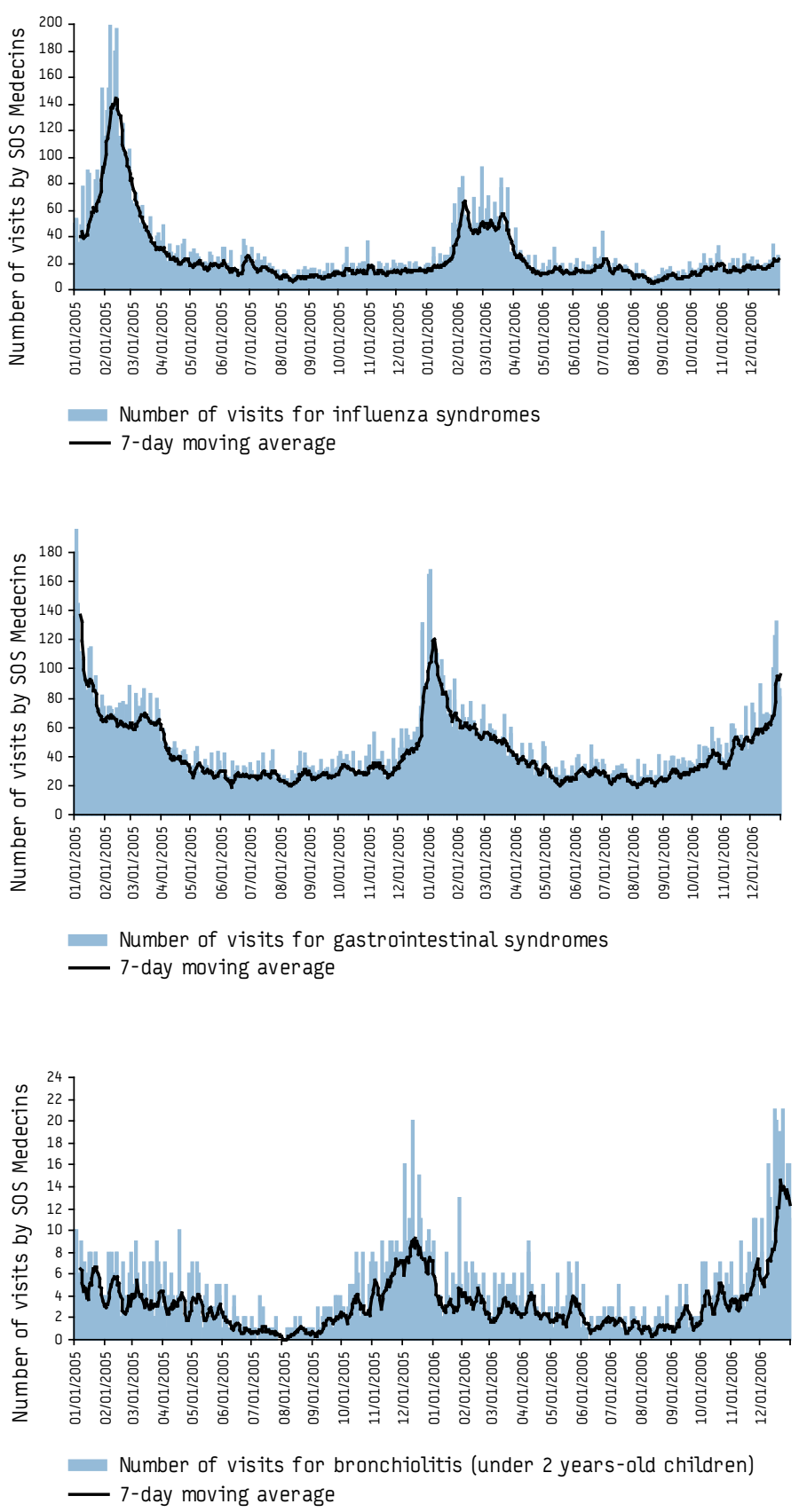

The $2 \sigma$ control limit $(C L)$ expressed as a multiple of the process standard deviation is given by:

$$
C L=\bar{x}+2 \frac{\overline{M R}}{d_{2}}
$$

where $\overline{\boldsymbol{x}}$ is the average of observations in previous weeks, $\overline{\boldsymbol{M R}}$ is the average of all the moving ranges of size 2 included in previous weeks and $d 2=1.128$. The moving range is defined as:

$$
M R_{i}=\left|x_{i}-x_{i-1}\right|
$$

which is the absolute value of first difference (e.g. the difference between two consecutive data points) of the data. The day of the week, public holidays and special events were taken into account in the process, comparing the counts for the current day with those for the comparable days and excluding special events from the average.

\section{Results}

\section{Global approach}

All visits made at home were collected and recorded in the database during the monitoring period from the beginning of 2005 to the end of 2006 . For $15 \%$ of the records, the database was not updated by the doctor at the end of the visit; with the result that the diagnosis was missing. Over the study period, 303,936 visits were recorded, with an average of 417 visits per day (varying from 198 to 818 ) including $10 \%$ of visits to children under two years of age and $11 \%$ to people of 75 years and older. More than an half $(56 \%)$ of patients were female. Global activity was influenced by important day-of-the-week and seasonal variations. The number of visits increased during the weekends and the winter.

\section{Syndromic approach}

\section{Surveillance of seasonal outbreaks}

The monitoring of the syndrome groups enables the surveillance of seasonal outbreaks such as influenza-like illness, gastrointestinal or bronchiolitis among young children (Figure 2). Epidemic periods were clearly identified on the curves reaching high peaks in winter seasons.

Figure 3 shows the weekly number of GP's visits for influenzalike illness and the same data collected by the sentinel network on two different scales [10]. The scales are different, as the SOS data only refer to the Bordeaux area, whereas the sentinel network data refer to the whole region of Aquitaine. Furthermore, the definition of influenza-like illness is not precisely the same: in the sentinel system, influenza-like illness is defined by a sudden fever $\left(>39^{\circ} \mathrm{C}\right.$ or $>102^{\circ} \mathrm{F}$ ) accompanied with myalgia and respiratory signs; whereas in the SOS Médecins system, it includes three diagnoses, gathered with the accordance of GP from the organization (influenza / influenza-like illness, fever and febrile symptoms, and viral disease other). Despite these differences, both sources of influenza syndrome data were strongly linked with a coefficient of correlation of 0.92 .

\section{Detecting unusual events: the example of the heat-wave of July 2006}

In July 2006, a significant heat-wave occurred in France and all public health services were placed on alert. In the Bordeaux area, the level of " warning and actions » of the Heat Health Watch Warning system [17] was activated from 16 to 27 July while the biometeorogical indicators reached the alert thresholds (Figure 4). 
At that time, the daily monitoring showed an acute increase in the number of GP visits for heat syndromes. This indicator was very sensitive to daily temperatures and the coefficients of correlation between both data sets were significant $(0.72 ; p<10-4$ for maximal temperature and 0.60; $p<10-4$ for minimal temperature). According to the statistical control chart analysis, threshold limits were exceeded from 14 July on, while the warning action level was activated from 16 to 27 July in the Bordeaux area.

\section{Discussion}

A new syndromic surveillance system based on GP's house visits was developed in the Bordeaux area and allowed to follow seasonal outbreaks and to detect unusual events.

\section{Attributes of the system}

This system has several important attributes [18] and advantages which demonstrate its validity and its performance for syndromic surveillance purposes [3].

Among the most important advantages is its capacity for the monitoring and of a wide range of specific health problems using the diagnosis made by the doctor at the end of the visit. While a number of syndromic surveillance systems based on emergency data are being developed and evaluated in different countries to improve early detection of outbreaks, most of them are based on a real-time transmission of chief complaints. Studies have shown that diagnosis data results in higher sensitivity and better agreement with expert reviewers than chief complaints for syndromic surveillance $[19,20]$.

Other advantages include the simplicity and the acceptability of the system which does not depend on additional voluntary reporting since all the GPs collect data on electronic notebooks for administrative reasons.

In terms of timeliness, the automated and real-time nature of the system allows the downloading of all visit information during the following day, making the data available for analysis within 24 hours of the GP's visit. Regarding flexibility, the system can adapt to changing information needs and can easily accommodate new health-related events or new diseases in the syndromes groups under surveillance. Another positive attribute is the quality of data: the use of ICPC-2-coded diagnosis ensures uniformity in the database. Differences in coding practices between the different GPs are possible but the use of syndrome groups should reduce the bias induced and increase sensitivity of the indicators.

Due to a lack of elementary data on the characteristics of the population who have access to SOS Medecins, the representativeness of the system could not be evaluated. it is therefore difficult to know how representative this population seen by SOS Medecins is. However, the observed trends of diseases and dynamics of outbreaks were coherent with the knowledge of the different diseases monitored and the high correlation in seasonal variation between our influenza-like illness episodes and the ones reported by the sentinel network provides one measure of assurance that our system identified relevant events.

\section{Contribution of the system in regional surveillance}

This new system complements existing surveillance programs by assessing a large part of episodes of illness which do not require hospital admissions, or identification of an etiologic agent. Until now, only hospital morbidity and mortality data have been used to monitor the health of populations in order to detect an outbreak in the Bordeaux area; the use of such data has limitations since, in addition to delays in reporting, there can be a delay between the detection of an outbreak from the number of cases reported by our system and the increase in the frequency of hospital morbidity or mortality data, which only reflects the most severe forms of the diseases. On the contrary, an increase of GP activity can be or more sensitive indicator since it can allow detecting an unusual health event as soon as it happens.

This surveillance system enables the monitoring of a large number of syndromes on a daily basis, which was not possible with the pre-existing Sentinel surveillance system. Furthermore, it includes enough GPs to obtain reliable data at the local level, whereas the sentinel system is mainly used for surveillance at the national level.
F I G U R E 3

Weekly number of visits for influenza-like illness made by SOS Médecins Bordeaux and declared by the sentinel network, 1 January 2005 - 31 December 2007

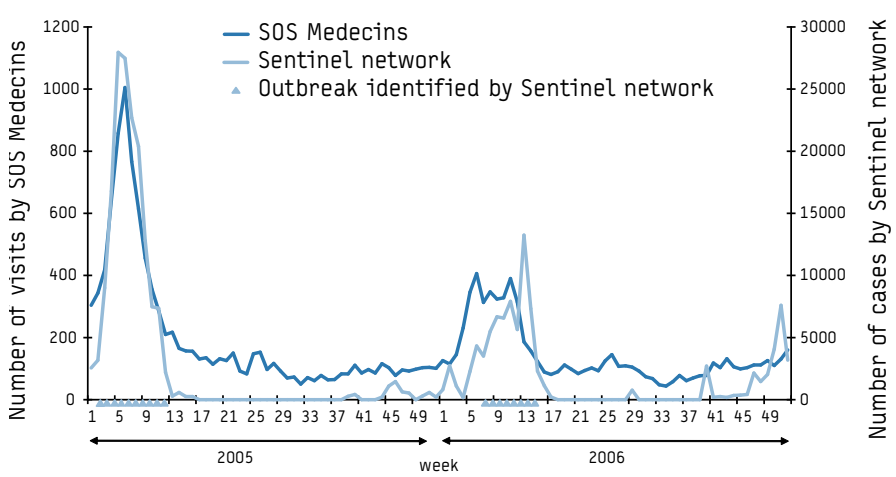

F I G U R E 4

Daily number of visits for heat syndromes made by SOS Médecins Bordeaux and temperatures, 1 June 2006 - 31 August 2006

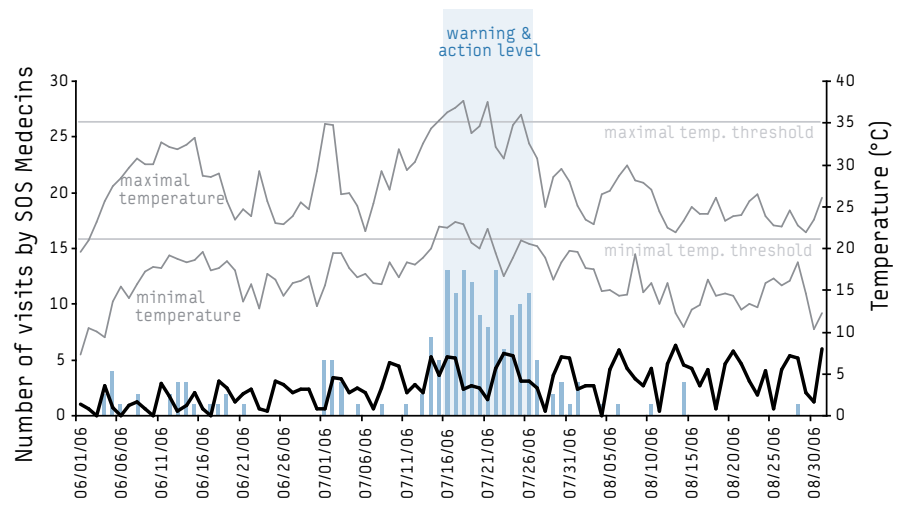

Number of visits for heat syndroms

- Alert threshold 
The availability of the postal code of the patient's residence is another benefit because the distribution of postal codes might allow spatial analysis and help in identifying an outbreak.

Another key point is that this syndromic surveillance system has the potential to show the importance of an early signal, increasing GPs' awareness of the need to bring any unusual event to the surveillance analyst's attention. This reinforces the communication links between clinicians and institutions in charge of health security. For example, in the context of the heat-wave that occurred in 2006, this system allowed to enlarge the preventive messages to the whole population since we showed that young adults as well as elderly people could be affected, contrary to what people believed. It also enabled an estimation of the heat-wave's health impact in order to provide objective data to politicians and help them take decisions.

Furthermore, the system has also been used several times to reassure health authorities that an outbreak has not occurred following a public health alert, such as the consumption of potentially dangerous food in a large part of the population of the area.

In conclusion, SOS Médecins surveillance can serve several different purposes including, monitoring disease patterns in order to detect outbreaks, providing detailed and timely information to health authorities, informing clinicians of conditions that are prevalent in their communities and supplementing current infectious disease surveillance systems.

For all these reasons, the development of tools - currently in progress - will allow the use of this system on a national basis in order to fulfill the same purposes in any other major French urban area.

\section{Acknowledgements}

The authors thank SOS Médecins Bordeaux for their collaboration in providing data and their very useful participation. We also appreciate the valuable participation of Lisa King and Christelle Vergeres for reading and commenting the article.

\section{References}

1. Fouillet A, Rey G, Laurent F et al. Excess mortality related to the August 2003 heat wave in France. Int Arch Occup Environ Health.2006;80(1):16-24.

2. Brücker G. Veille sanitaire: nouveau système, nouveaux enjeux. Editorial. In French. Bulletin épidémiologique hebdomadaire. 2005;27-28:133. Available from: http://www.invs.sante.fr/beh/2005/27_28/beh_27_28_2005.pdf

3. Henning KJ. What is Syndromic Surveillance? MMWR Morb Mortal Wkly Rep. 2004 Sep 24;53 Suppl:5-11.

4. Lazarus R, Kleinman KP, Dashevsky I, DeMaria A, Platt R. Using automated medical records for rapid identification of illness syndromes (syndromic surveillance): the example of lower respiratory infection. BMC Public Health. 2001;1:9.

5. Heffernan R, Motashari F, Das D et al. New York City syndromic surveillance systems. MMWR Morb Mortal Wkly Rep. 2004 sep 24;53 Suppl:23-27.

6. Lewis MD, Pavlin JA, Mansfield JL et al. Disease outbreak detection system using syndromic data in the greater Washington DC area. Am J Prev Med. 2002 Oct;23(3):180-186.

7. Bork KH, Klein BM, Mølbak K, Trautner S, Pedersen UB, Heegaard E. Surveillance of ambulance dispatch data as a tool for early warning. Euro Surveill. 2006;11(12):pii=669. Available from: http://www.eurosurveillance.org/ ViewArticle.aspx?ArticleId $=669$
8. Doroshenko A, Cooper D, Smith G, Chinemana F, Verlander N, Nicoll A. Evaluation of Syndromic Surveillance Based on National Health Service Direct derived data--England and Wales. MMWR Morb Mortal Wkly Rep. 2005 Aug 26;54 Suppl:117-122.

9. Josseran L, Nicolau R, Caillère N, Astagneau P, Brücker G. Syndromic surveillance based on emergency department activity and crude mortality: two examples. Euro Surveill. 2006;11(12):pii=668. Available from: http://www. eurosurveillance.org/ViewArticle.aspx?ArticleId $=668$

10. Flahault A, Blanchon T, Dorleans Y, Toubiana L, Vibert JF, Valleron AJ. Virtual surveillance of communicable diseases: a 20-year experience in France. Stat Methods Med Res. 2006;15(5):413-421.

11. Carrat F, Flahault A, Boussard E, Farran N, Dangoumau L, Valleron AJ. Surveillance of influenza-like illness in France. The example of the 1995/1996 epidemic. J Epidemiol Community Health. 1998;52 Suppl 1:32S-38S.

12. King DA, Peckham C, Waage JK, Brownlie J, Woolhouse ME. Epidemiology.Infectious diseases: preparing for the future. Science. 2006;313 (5792):1392-1393.

13. Centers for Disease Control and Prevention, Atlanta, US. Syndromic surveillance for bioterrorism following the attacks on the World Trade Center-New York City, 2001. MMWR Morb Mortal Wkly Rep.2002 Sep 11; 51: 13-15.

14. Bentsen BG. International classification of primary care. Scand J Prim Health Care. 1986 Feb;4(1):43-50.

15. Montgomery, D.C. 2005.Introduction to Statistical Quality Control, 5th Ed. John Wiley \& Sons, New York,NY.

16. NIST/SEMATECH e-Handbook of Statistical Methods. Available from: http://www. itl.nist.gov/div898/handbook/pmc/section3/pmc322.htm

17. Pascal M, et al. France's heat health watch warning system. Int J Biometeorol. 2006;50(3):144-53.

18. Centers for Disease Control and Prevention (CDC).Updated guidelines for evaluating public health surveillance systems: recommendations from the Guidelines Working Group. MMWR Morb Mortal Wkly Rep. 2001; 50(RR13):1-35.

19. Reis BY, Mandl KD. Syndromic surveillance: The effects of syndrome grouping on model accuracy and outbreak detection. Ann Emerg Med. 2004:44:235-241.

20. Beitel AJ, Olson KL, Reis BY, Mandl KD. Use of emergency department chief complaint and diagnostic codes for identifying respiratory illness in a pediatric population. Pediatr Emerg Care. 2004 Jun;20(6):355-360.

This article was published on 19 June 2008.

Citation style for this article: Flamand C, Larrieu S, Couvy F, Jouves B, Josseran L, Filleul L. Validation of a syndromic surveillance system using a general practitioner house calls network, Bordeaux, France. Euro Surveill. 2008;13(25):pii=18905. Available online: http://www.eurosurveillance.org/ViewArticle.aspx?ArticleId=18905 